\title{
Cognitive and emotional control in college drinkers and the relationship to comorbid disorders
}

\author{
Barbara C. Banz ${ }^{1 *}$ and Deana B. Davalos ${ }^{2}$ \\ ${ }^{1}$ Yale University School of Medicine, Church Street, $7^{\text {th }}$ Floor, New Haven, CT 06519, USA \\ ${ }^{2}$ Colorado State University, Fort Collins, CO 80523, USA
}

\begin{abstract}
Introduction: Alcohol abuse during university years is associated with long term deficits and higher rates of alcohol use disorders, a pervasive psychiatric problem. Due to the ongoing neuromaturation and cognitive development youth drinking may impact and be impacted by disordered thinking; factors which may relate to comorbid psychiatric disorders.

Participants: One hundred and ninety seven university students were recruited and categorized in to different levels of alcohol consumption based on two self-report measures.

Method: Cognitive performance was assessed through six tasks: Wisconsin Card Sorting Test, Delay Discounting Task, One Touch Stockings of Cambridge, Trail Making Task (A and B), the Behavioral Rating Inventory of Executive Function, and the Dysexecutive Questionnaire.

Results/Conclusions: Significant findings were noted in two MANOVAs comparing various drinking groups and nondrinkers; both $\mathrm{p}<.05$. Primary differences were noted in subscales of the Behavioral Rating Inventory of Executive Function and the Dysexecutive Questionnaire related to metacognition and self-regulation. Disparities in Wisconsin Card Sorting Task performance were also significant.

Though the deficits were not as vast as hypothesized, the inability for binge drinkers to complete an equal number of categories in the WCST as their nondrinking peers holds interesting conclusions. Those which are discussed relate to binge drinkers' similarities in dysfunction between drinkers and mental health disorders.
\end{abstract}

\section{Introduction}

Alcohol use disorders (AUD) are widespread, and possibly the most preventable psychiatric disorder [1]. Alcohol abuse is particularly pervasive during college [2]. College drinkers are at higher risk for deleterious behavior [3] and AUDs [4]. Therapies exist for AUD and reducing university drinking, though widespread comorbidity with other mental health disorders such as depression and anxiety reduces efficacy of these methods $[5,6]$.

Depression and anxiety present with altered executive functioning and emotion regulation $[7,8]$. In typical college-aged individuals, the regions which facilitate executive functioning and emotion regulation, the prefrontal cortex (PFC) and limbic system, are maturing [9]. During maturation, these regions are particularly sensitive to the neurotoxic effects of alcohol $[10,11]$. This is evident through executive and cognitive functioning measures [12]. As such, a multifaceted understanding of executive functioning in college drinkers is needed to understand potential confounding comorbidities to develop more effective interventions.

Our study aimed to develop our understanding of the neurocognitive profile of college drinkers that may elucidate functioning similarities between college drinking and other mental illnesses that are prevalent in college students. The current measures allowed for the evaluation of interactions between separate processes, cognitive/executive functioning, and behavioral/psychological factors. These interactions were thought to be evident due to differences in drinking risk factors associated with the deficits in interpersonal awareness, constructs which are relate to various cognitive deficits and the PFC [13].

\section{Methods and Materials}

Participants: One hundred ninety seven (75 males) participants were recruited from Introduction to Psychology courses at a midsize university. Individuals received extra credit or class credit for attending the study in order to fulfill course research requirements. Of this group, those that were over the age of 25 or did not report an age were excluded from further analyses (17 total). In accordance with previously used practices, those individuals with a history of neurological or psychological diagnoses (68) were not included in the initial data analyses. Additionally, in order to control for confounds due to familial drug or alcohol addiction or abuse, those with this history were excluded (24 total).

Procedure: Each participant was asked to read and complete an approved consent form, and a demographics form which included questions regarding sex-specific binge-drinking (e.g. "If you are a female, please answer the following: Have you consumed 4 or more

Correspondence to: Barbara C. Banz, Yale University School of Medicine, Church Street, 7th Floor, New Haven, CT 06519, USA, Tel: 973 879-9931; Fax: 203 737-3591; E-mail: barbara.banz@yale.edu

Key words: University, alcohol, depression, anxiety, executive function, emotion, PFC, ACC

Received: May 26, 2016; Accepted: June 20, 2016; Published: June 22, 2016 
drinks on at least one occasion during the 2 weeks before survey? If so, how many drinks in one sitting?"). This specific questioning was included as binge-drinking it the most prevalent form $[2,14]$ and most deleterious pattern of drinking in a maturing population [11]. The demographic form and the following tasks were administered in a counterbalanced order across participants.

\section{Alcohol Use Disorder Identification Test}

The Alcohol Use Disorder Identification Test (AUDIT) [15,16] was used to assess a more detailed view of drinking and consequential behavior within these individuals in order to more appropriately categorize individuals in to drinking groups.

\section{Executive Functioning Measures}

Wisconsin Card Sorting Test (WCST): The WCST, a computerized card sorting task during which participants sorted cards based on three categories: color, form, or number. Four stimulus cards allowed individuals to see representations of the categories as one red circle, two green stars, three blue squares, and four yellow plus signs (+). Participants were told that they will be informed whether their categorization is "correct" or "wrong", however, no direction was given as to which category is correct; the correct category changes after ten trials. [Strauss Sherman Spreen 2006]. The number of categories completed was the parameter used for analysis.

Trail Making Task (TMT): This paper and pencil neuropsychological measure requires participants connect dots in a sequential manner. Two versions were administered to each participant; version A asked participants to connect dots labeled 1-25, version B requires connecting in an alphanumeric manner, A-1 through L-13. The ratio calculated from the time to successfully complete trials A and B was used for analyses in the current study; greater impairment is reflected through larger ratios. [17]

One Touch Stockings of Cambridge (OTS): During OTS administration, individuals were asked to report how many moves it would take to arrange a given set of billiard balls in stockings to mirror an example on a computer tablet. Unlike SOC, one does not get the opportunity to move the billiard balls, items are rearranged mentally. [11] The two outcome measures used in this investigation were mean latency to correct choice and mean choices to correct choice.

Delay-Discounting Task (DDT): The DDT was developed by [18] to assess individual choices. Over 27 items, participants were asked to choose if they would like to receive a smaller, immediate reward (SIR) or a larger, delayed reward (LDR). The LDRs were divided in to three categories; S: \$25-35, M: \$50-60, L: \$75-85. Behavioral Ratings Inventory of Executive Function - Adult Version (BRIEF-A): Comprised of 75 items, this measure is effective at evaluating the everyday aspects of executive function [16].

Dysexecutive Questionnaire (DEX): The DEX is a 20-item questionnaire assesses behavior, cognition, motivation, and emotion and personality; cognitive regulation [19]. Each item is scored on a 5 point Likert scale, $0-4$ for "Never" to "Very Often", higher scores implying greater dysexecutive function.

\section{Analytic Approach}

A multivariate analysis of variance (MANOVA) was used in order to evaluate differences between three groups (ND, BD, PBD) and the potential effects the current variables had on the other outcome measures. In order to explore differences within binge-drinkers further, a second MANOVA was used (groups: ND, LBD, HBD, PBD). Significance was set with alpha level .05 using Wilks' Lambda effects.

\section{Results and Discussion}

After consideration of the demographic exclusion factors, 88 individuals remained for continued analysis. Our initial groupings were non-drinkers (37 total; ND), binge-drinkers (30 total; BD), and problematic binge-drinkers (21 total; PBD). Individuals categorized in these groups met the following criteria: ND (no binge drinking reported through 4/5 questionnaire and zero scores on AUDIT), BD (binge drinking reported through 4/5 questionnaire and AUDIT scores between one and seven), and PBD (those binge drinkers which also scored an eight or above on the AUDIT with binge drinking reported through the 4/5 demographic question).

To evaluate potential differences in very low and moderate drinkers we reevaluated our $\mathrm{BD}$ categorization. These individuals were categorized as low binge-drinkers (12 total; LBD) and high bingedrinkers (18 total; HBD) Individuals categorized in these groups met the following criteria: LBD (binge drinking reported through $4 / 5$ questionnaire and AUDIT scores between one and four), HBD (binge drinking reported through 4/5 questionnaire and AUDIT scores between five and seven). These divided groups allowed for a more detailed view of individuals that still binge drink but have divergent rates.

The initial MANOVA model was significant $\mathrm{F}(28,144)=1.64$, $\mathrm{p}=.03$. Significant differences were found in the DEX subscales Metacognition $(\mathrm{F}(2,85)=3.10, \mathrm{p}=.03$; PBD scores were significantly greater than ND $(\mathrm{p}<.01))$ and Behavioral-Emotional Self-Regulation $(\mathrm{F}(2,85)=3.68, \mathrm{p}=.03$; PBD significantly higher than ND $(\mathrm{p}<.01)$ and $\mathrm{BD}(\mathrm{p}<.05))$, and the BRIEF-A subscales $\mathrm{MI}(\mathrm{F}(2,85)=3.55$, $\mathrm{p}$ $=.03$; scores were significantly higher for PBD than $\mathrm{ND}(\mathrm{p}<.05)$ and $\mathrm{BD}(\mathrm{p}<.05))$ and $\mathrm{BRI}(\mathrm{F}(2,85)=4.43, \mathrm{p}=.02$; scores were significantly higher for PBD than ND $(\mathrm{p}<.05)$ and BD $(\mathrm{p}<.01)$. Comparisons can be found in Figure 1.

Significant differences were also found in the second MANOVA $(\mathrm{F}(42,211.39)=1.49, \mathrm{p}=.04)$. Again, significant differences were found within the DEX Metacognition subscale $(\mathrm{F}(3,84)=3.10, \mathrm{p}=.03$; PBD significantly higher than ND $(\mathrm{p}<.01)$ and LBD $(\mathrm{p}<.05))$, and the BRIEF-A subscales $\mathrm{MI}(\mathrm{F}(3,84)=2.83, \mathrm{p}=.04$; PBD significantly higher than $\mathrm{ND}(\mathrm{p}<.05))$ and $\mathrm{HBD}(\mathrm{p}<.01)$ and $\mathrm{BRI}(\mathrm{F}(3,84)=3.18$, $\mathrm{p}=.03$; PBD significantly higher than ND $(\mathrm{p}<.05)$ and HBD $(\mathrm{p}<$ $.01)$ ). Additionally, WCST categories was significant $(\mathrm{F}(3,84)=3.17$, $\mathrm{p}$ $=.03$; LBD significantly worse than $\mathrm{ND}(\mathrm{p}<.05)$ and HBD $(\mathrm{p}<.01)$. Comparisons can be found in Figure 2.

The nonlinear relationship between alcohol consumption and the current measures suggest potential similarities between ND and HBD, and LBD and PBD. Patterns in WCST performance may relate to task completion through trial and error rather than evaluating, planned manner, suggestive of anterior cingulate cortex (ACC) and PFC impairment. These data also support similarities within depression and anxiety related populations [20,21]. The ACC, part of the limbic system, has been related to impulse control, reward anticipation, decision making, social cognitions, and emotion, all facets prevalent during neurodevelopment [9], risky decisions [22,23] and mental health disorders [7,8]. Differences in ACC activity have been suggested as a risk-factor for alcohol use in adolescents [24,25]. This disordered thinking suggests problem drinking populations may have difficulty adjusting to changes in their social setting, and physiological and 


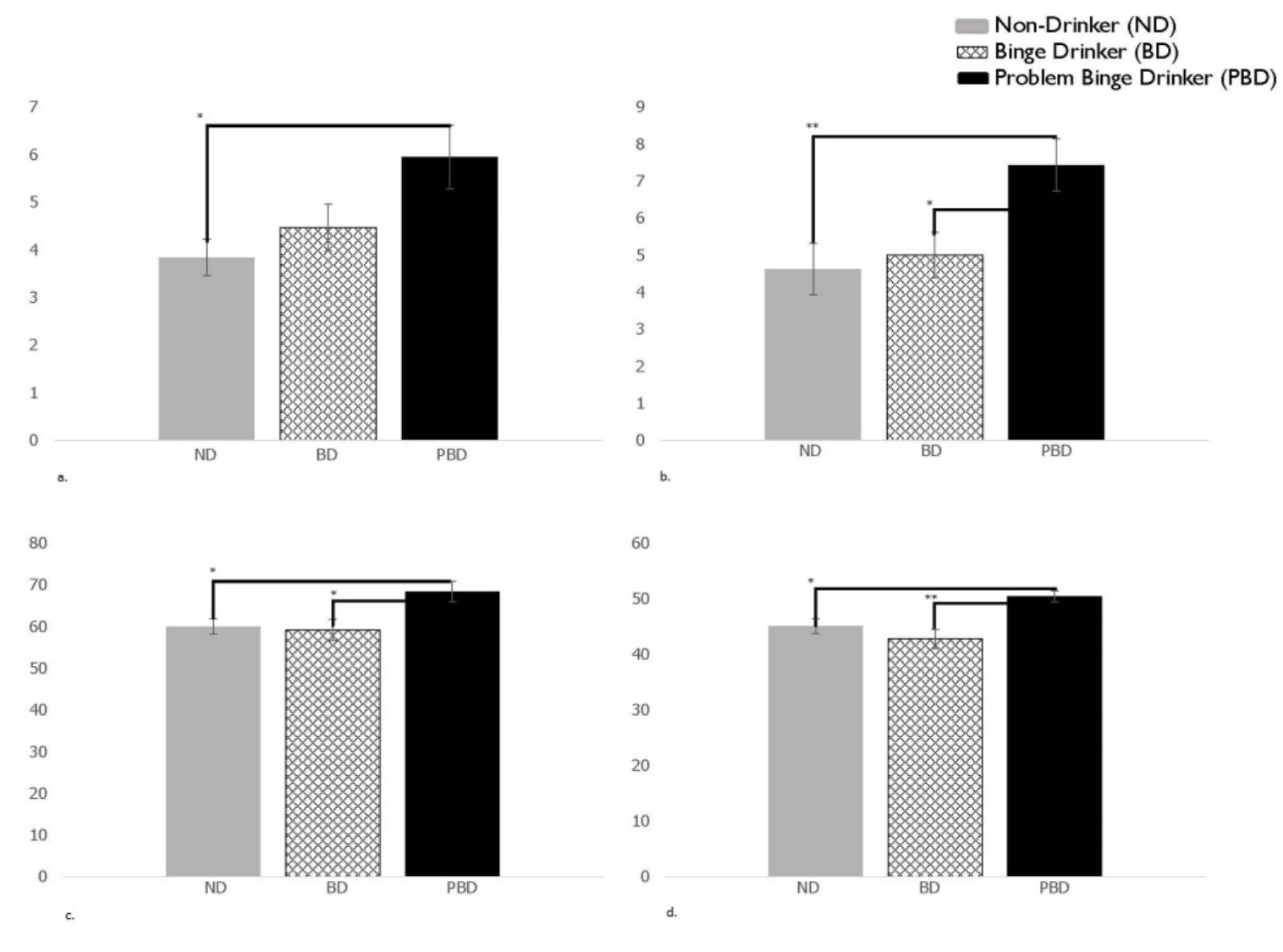

Figure 1. Initial MANOVA model.

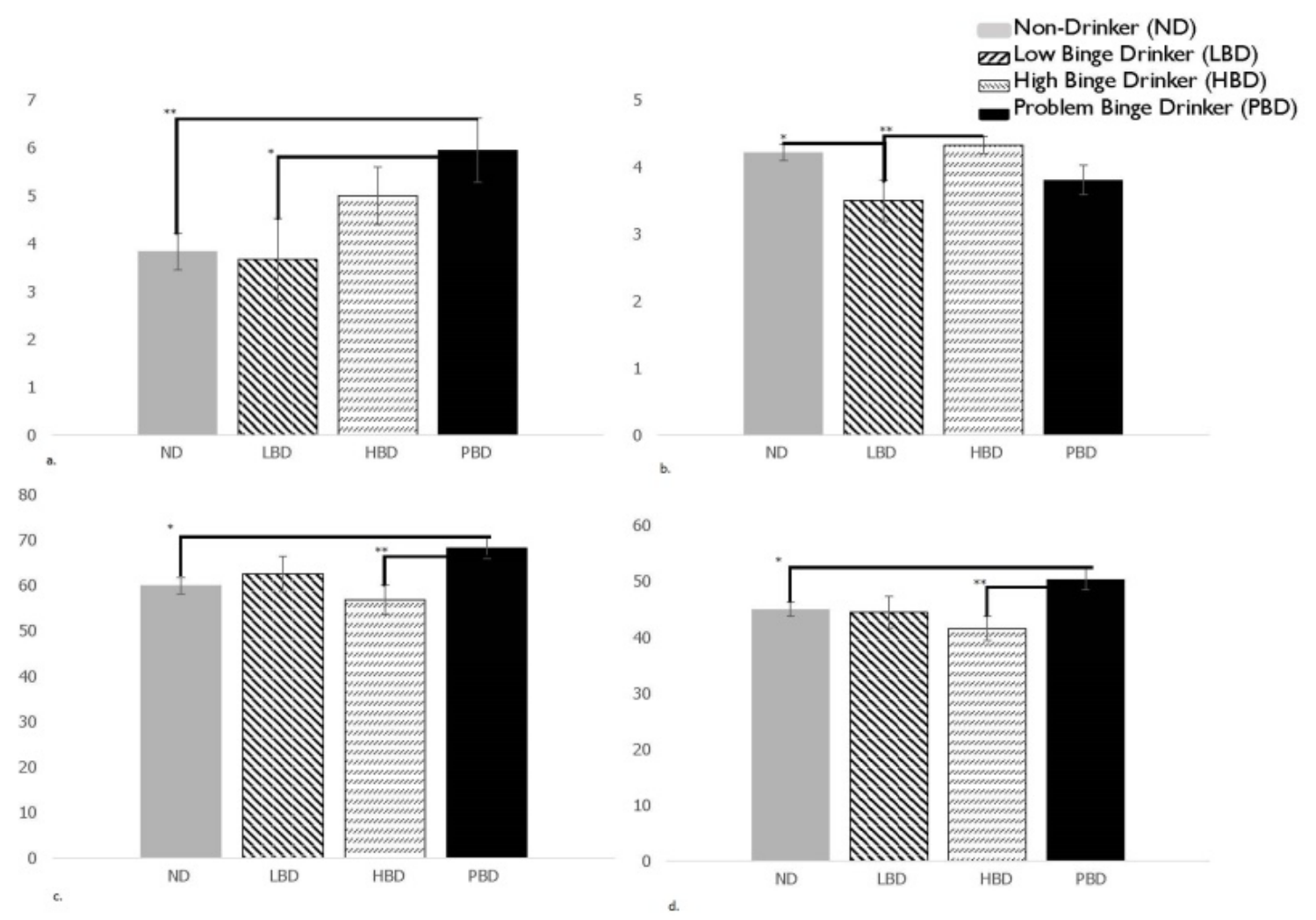

Figure 2. Second MANOVA model. 
psychological changes, including those due to alcohol consumption.

Further support is found within the emotion component of the DEX. This is emphasized by the high comorbidity of depression and anxiety in college drinkers [26]. Additionally, these data relate to motivation to drink in college students. Motivations to drink for college students are typically categorized as enhancement, social, conformity, and coping [27], with particular concern for those drinking to cope or enhance feelings. The motivations "drinking to cope" or "enhance feelings" are associated with underlying emotion regulation issues, long-term AUD, and other disorders [28] due to the development of faulty constructs. As such, the consideration of a relationship between monitoring deficits (metacognition), emotional regulation, and motivation to drink may help develop focused intervention methods.

Though we feel our methodological and analytical methods were sound, certain limitations need be noted. First, a formal diagnostic screen was not employed (e.g., a version of the SCID or MINI) as such, we cannot directly compare relationships with a formal clinical diagnosis. However, individuals who reported a previous history of a psychological disorder were excluded, strengthening our arguments of similarities between college alcohol users and mental health. Additionally, due to the nature of our sample (volunteers, no pre-screen) our samples were not adequately proportioned to evaluate gender-related differences. This facet is becomes increasingly important when considering motivation, and trajectory differences [31]. Therefore, we feel that future studies should employ a recruited population with more equal representations of gender.

College drinkers are a unique population. Alcohol consumption during these formative years is often thought of as "coming of age" behavior [29]. However, individuals who partake are at an increased risk-of developing a long-term AUD [30,31] and higher depression and anxiety later in life [32]. Therefore, studies, such as the current investigation, are necessary in order to understand underlying dysfunction. This will lead to the development of intervention methods which would provide long-term reduction in behavior, and reduce the negative impact [32].

In sum, through the combined use of self-report and task-based evaluation of executive functions, cognitive control, and neurocognition we believe our data offer a valuable insight into a pervasive early life addiction precursor. With most AUD originating during this this time $[30,33]$, and high comorbidity with mental health disorders [34,35] disentangling factors which may prevent an addiction are imperative. Disordered thinking related to dysfunctional emotional processing, regulation, self-monitoring, and awareness noted in the current study offer important suggestions for future directions, experimentally and therapeutically.

\section{Authorship and Contributions}

Both authors declare substantive intellectual contributions to the current work. BCB developed testing methods, performed data analysis, and majority manuscript preparation. DBD assisted in data interpretation and manuscript preparation.

\section{Funding}

Writing of this manuscript was supported in part by NIAAA and NIDA T32 Grants ((BCB) AA015496; DA007238). NIAAA and NIDA had no role in the study design, collection, analysis or interpretation of the data, writing of the manuscript, or the decision to submit the paper for publication.

\section{Declarations of Conflict}

Authors declare no conflicts of interest.

\section{References}

1. Substance Abuse and Mental Health Services Administration. (2014). Results from the 2013 National Survey on Drug Use and Health: Summary of National Findings, NSDUH Series H-48, HHS Publication No. (SMA) 14-4863. Rockville, MD: Substance Abuse and Mental Health Services Administration.

2. O'Malley PM, Johnston LD (2002) Epidemiology of alcohol and other drug use among American college students. J Stud Alcohol Suppl: 23-39. [Crossref]

3. Grigsby TJ, Forster M, Unger JB, Sussman S (2016) Predictors of alcohol-related negative consequences in adolescents: A systematic review of the literature and implications for future research. $J$ Adolesc 48: 18-35.

4. American Psychiatric Association (2013) Diagnostic and statistical manual of mental disorders (5th ed.). Arlington, VA: American Psychiatric (Grigsby et al. 2016) Publishing.

5. Moos RH, Moos BS (2006) Rates and predictors of relapse after natural and treated remission from alcohol use disorders. Addiction 101: 212-222. [Crossref]

6. Pedrelli P, Shapero B, Archibald A, Dale C (2016) Alcohol use and depression during adolescence and young adulthood: a summary and interpretation of mixed findings. Curr Addict Rep 3: 91-97. [Crossref]

7. Forbes EE, May CJ, Siegle GJ, Ladouceur CD, Ryan ND, Carter CS, Birmaher B, Axelson DA, Dahl RE (2006) Reward-related decision-making in pediatric major depressive disorder: An fMRI study. J Child Psychol Psychiatry 47: 1031-1040.

8. Robinson OJ, Vytal K, Cornwell BR, Grillon C (2013) The impact of anxiety upon cognition: perspectives from human threat of shock studies. Front Hum Neurosci 7: 203. [Crossref]

9. Spear LP (2013) Adolescent neurodevelopment. J Adolesc Health 52: S7-13. [Crossref]

10. Guerri C, Pascual M (2010) Mechanisms involved in the neurotoxic, cognitive, and neurobehavioral effects of alcohol consumption during adolescence. Alcohol 4: 15-26.

11. Crews F, He J, Hodge C (2007) Adolescent cortical development: a critical period of vulnerability for addiction. Pharmacol Biochem Behav 86: 189-199. [Crossref]

12. Squeglia LM, Jacobus J, Tapert SF (2014) The effect of alcohol use on human adolescent brain structures and systems. Handb Clin Neurol 125: 501-510.

13. Decety J, Sommerville JA (2003) Shared representations between self and other: a social cognitive neuroscience view. Trends Cogn Sci 7: 527-533. [Crossref]

14. Naimi TS, Brewer RD, Mokdad A, Denny C, Serdule MK, et al. (2003) Binge Drinking Among US Adults. Journal of the Americal Medical Association 289: 5.

15. Babor TF, Higgins-Biddle JC, Saunders JB, Monteiro MG (2001) The alcohol use disorders identification test: guidelines for use in primary care, Geneva, World Health Organization.

16. Balzano J, Chiaravalloti N, Lengenfelder J, Moore N, DeLuca J (2006) Does the scoring of late responses affect the outcome of the paced auditory serial addition task (PASAT)? Arch Clin Neuropsychol 21: 819-825. [Crossref]

17. Reitan RM (1958) Validity of the trail making test as an indicator of organic brain damage. Perceptual Motor Skills 8: 271-276.

18. Kirby KN, Marakovic NN (1996) Delay-discounting probabilistic rewards: Rates decrease as amounts increase. Psychonomic Bulletin Rev 3: 100-104.

19. Wilson BA, Alderman N, Burgess PW, Emslie H, Evans JJ, et al. (1996) Behavioural assessment of the Dysexecutive Syndrome (BADS). Journal of Occupational Psychology. Employment and Disability 5: 33-37.

20. Channon S (1996) Executive dysfunction in depression: the Wisconsin Card Sorting Test. J Affect Disord 39: 107-114. [Crossref]

21. Micco JA, Henin A, Biedermann J, Rosenbaum JF, Petty C, et al. (2009) Executive functioning in offspring at risk for depression and anxiety. Depress Anxiety 26: 780-90.

22. Balogh KN, Mayes LC, Potenza MN (2013) Risk-taking and decision-making in youth: relationships to addiction vulnerability. J Behav Addict 2. [Crossref]

23. Figner B, Mackinlay RJ, Wilkening F (2009) Affective and Deliberative Processes in Risky Choice: Age Differences in Risk Taking in the Columbia Card Task. Journal of Experimental Psychology: Learning, Memory, and Cognition 3: 21. 
24. Steinberg L (2008) A Social Neuroscience Perspective on Adolescent Risk-Taking. Dev Rev 28: 78-106. [Crossref]

25. Vollstädt-Klein S, Hermann D, Rabinstein J, Wichert S, Klein O, et al. (2010) Increased activation of the ACC during a spatial working memory task in alcohol-dependence versus heavy social drinking. Alcohol Clin Exp Res 34: 771-776. [Crossref]

26. Pedrelli P, Shapero B, Archibald A, Dale C (2016) Alcohol use and depression during adolescence and young adulthood: a summary and interpretation of mixed findings. Curr Addict Rep 3: 91-97. [Crossref]

27. Cooper LM (1994) Motivations for alcohol use among adolescents: Development and validation of a four-factor model. Psychol Assessment 6: 117-128.

28. Blevins CE, Abrantes AM, Stephens RS (2016) Motivational pathways from antecedents of alcohol use to consequences: a structural model of using alcohol to cope with negative affect. Am J Drug Alcohol Abuse. [Crossref]

29. Schulenberg J, O'Malley PM, Bachman JG, Wadsworth KN, Johnston LD (1996) Getting drunk and growing up: trajectories of frequent binge drinking during the transition to young adulthood. J Stud Alcohol 57: 289-304. [Crossref]

30. DeWit DJ, Adlaf EM, Offord DR, Ogborne AC (2000) Age at first alcohol use: a risk factor for the development of alcohol disorders. Am J Psychiatry 157: 745-750. [Crossref]

31. Petit G, Kornreich C, Verbanck P, Cimochowska A, Campanella S (2013) Why is adolescence a key period of alcohol initiation and who is prone to develop long-term problem use?: A review of current available data. Socioaffective Neuroscience \& Psychology 21: 890.

32. Jeanblanc J (2015) Comorbidity between Psychiatric Diseases and Alcohol Use Disorders: Impact of Adolescent Alcohol Consumption. Current Addiction Reports 293-301.

33. Grigsby TJ, Forster M, Unger JB, Sussman S (2016) Predictors of alcohol-related negative consequences in adolescents: A systematic review of the literature and implications for future research. $J$ Adolesc 48: 18-35. [Crossref]

34. Clark DB, Pollock N, Bukstein OG, Mezzich AC, Bromberger JT, et al. (1997) Gender and comorbid psychopathology in adolescents with alcohol dependence. $J$ Am Acad Child Adolesc Psychiatry 36: 1195-1203. [Crossref]

35. Birrell L, Newton NC, Teesson M, Slade T (2016) Early onset mood disorders and first alcohol use in the general population. $J$ Affective Disorders 200: 243-249.

Copyright: (C2016 Banz BC. This is an open-access article distributed under the terms of the Creative Commons Attribution License, which permits unrestricted use, distribution, and reproduction in any medium, provided the original author and source are credited. 